\title{
Molecular Characterization of Kiwifruit (Actinidia) Cultivars and Selections Using SSR Markers
}

\author{
Yiqi Zhen, Zuozhou Li, and Hongwen Huang1 \\ Wuhan Botanical Garden/Wuhan Institute of Botany, The Chinese Academy of Sciences, Wuhan, Hubei \\ 430074, P.R. China \\ Ying Wang \\ Department of Plant Breeding, Cornell University, Ithaca NY, 14853
}

AdDitional INDEX WORDs. DNA fingerprinting, genetic diversity, cultivar identification, A. chinensis, A. deliciosa

\begin{abstract}
AвSTRact. Forty-eight kiwifruit cultivars and selections, representing more than $90 \%$ of total world kiwifruit production, were investigated using nine SSR markers to establish genetic identities, and evaluate genetic diversity and relatedness. These nine SSRs were polymorphic and a total of 213 alleles were detected, resulting in a mean number of 23.7 alleles per locus, ranging from nine to 38 alleles. One hundred and thirty-three alleles were found to be common to both $A$. chinensis and $A$. deliciosa, while 33 and 36 were specific to $A$. chinensis and $A$. deliciosa, respectively. In addition, 34 alleles were specific to one single genotype and provided a set of valuable alleles for cultivar identification. A single SSR locus UDK 96-414 could differentiate all 48 genotypes except two presumable clones. Mean number of alleles per locus (A), percentage of polymorphic loci $(P)$, and direct count heterozygosity $\left(H_{0}\right)$ assessed for each genotype over all loci revealed considerable differences among these 48 genotypes. On average, $A=2.6, P=89.4 \%$ and $H_{0}=0.546$ were found in A. chinensis cultivars, while $A=3.5, P=97.0 \%$ and $H_{0}=0.671$ in $A$. delicios $a$ cultivars. Consensus fingerprint profiling using SSR markers is a useful and reliable method for establishing genetic identities of kiwifruit cultivars and selections. It also improves evaluation effectiveness of genetic diversity and relatedness compared to RAPD markers.
\end{abstract}

Commercial kiwifruit production is based on two Actinidia species, A. deliciosa C.F. Liang et A.R. Ferguson and A. chinensis Planch. The genus Actinidia Lindl. comprises 66 species and about 118 taxa with a remarkably wide natural range extending from the tropics (latitude $\left.0^{0}\right)$ to cold temperate regions $\left(50^{\circ} \mathrm{N}\right)$. All these species occur naturally in China except four species that are native to neighboring countries: A. strigosa Hook \& Thoms. in Nepal, A. petelotii Diels in Vietnam, A. hypoleuca Nakai and A. rufa (Sieb. et Zucc.) Planch ex Miq. in Japan (Huang et al., 2000). Since the first seed introduction of A. deliciosa was made from China into New Zealand in 1904, the economic potential of kiwifruit has been extensively exploited (Ferguson and Bollard 1990). Currently, the international kiwifruit industry has achieved more than 100,000 hectares with annual production of one million tons (Huang and Ferguson, 2001).

China has a long history of local consumption of the Actinidia as fresh fruits and Chinese herbal medicines for centuries (Cui, 1993). The successful development of kiwifruit industries, first in New Zealand and then in other countries, has stimulated China's interest in the potential of native Actinidia species for commercial production. A government organized nationwide selection program was initiated in China in 1977. This program had two missions: 1) to conduct a national germplasm survey and inventory of natural resources of Actinidia; 2) to select genotypes superior to the 'Hayward' cultivar developed in New Zealand, the single cultivar planted worldwide during the 1970s. As a result, more than 1400 genotypes were selected from wild populations of A. chinensis, A. deliciosa, and A. arguta. Most of

Received for publication 25 July 2003. Accepted for publication 17 Dec. 2003. This research was supported by NSFC grant 30070062 , the CAS-project KSCX2SW-104.

${ }^{1}$ Professor of plant genetics and breeding, Wuhan Botanical Garden/Wuhan Institute of Botany, The Chinese Academy of Sciences, Wuhan, Hubei 430074, P.R. China. Corresponding author; e-mail hongwen@public.wh.hb.cn. these selections were evaluated in experimental trials, regional tests, and replicated trials on a commercial scale, leading to the development of 57 cultivars and a large number of advanced selections. The outcome of the program made an unique situation for the Chinese kiwifruit industry because diverse varieties were planted for commercial production (Huang and Ferguson, 2001). Most of the cultivars in China are direct selections from wild populations of $A$. chinensis and A. deliciosa. These cultivars and advanced selections have many improved commercial traits such as large fruit size (average 80 to $100 \mathrm{~g}$ ) with desirable appearance, high vitamin C content (250 to $350 \mathrm{mg} / 100 \mathrm{~g}$ fresh flesh), high soluble solids content $(\approx 26 \%)$, and long storage life at $1{ }^{\circ} \mathrm{C}(4$ months $)$ or at room temperature $(40 \mathrm{~d})$. Some cultivars and selections are very precocious and set flowers in the first year after grafting, others are early producers $(17 \mathrm{~kg} /$ plant of 3 years old), cold hardy, drought tolerant, and with wider adaptability. Some selections are particularly valuable because of different maturity, excellent tastes, various flesh colors, and special uses for processed products (Huang, 1999).

Three major Actinidia repositories have been established at Wuhan, Guiling, and Lushan in China as a result of increased attention to germplasm conservation. The national germplasm repository for Actinidia and the breeding program for kiwifruit cultivar improvement were established in 1978 at the Wuhan Institute of Botany (WIB) with the goals of conserving natural resources of Actinidia in China and developing superior cultivars. This repository is the largest for the conservation of Actinidia genetic resources. The living collection at WIB comprises 57 taxa of 36 species consisting of more than 200 accessions and 900 selections and lines of breeding progeny. However, for a plant species at an early stage of domestication (such as kiwifruit) to meet market demand for larger and sweeter-tasting fruit, new cultivar development from long-term breeding programs is required and characterization of germplasm collections is prerequisite for efficient maintenance and use of Acinidia genetic resources. Of 
great concern to kiwifruit breeders and germplasm custodians is the limited genetic diversity contained in commercially important cultivars and selections. Molecular fingerprinting can provide accurate genetic information for future breeding and germplasm collection efforts (Cantini et al., 2001; Hokanson et al., 1998; Lamboy and Alpha, 1998). Improving the integrity and efficiency of the Actinidia repository management is a part of our long-term commitment to ex situ conservation and evaluation of Actinidia genetic germplasm.

Simple sequence repeats (SSRs) have recently been used successfully as genetic markers for identifying cultivars and germplasm accessions due to their co-dominant inheritance and hypervariability in fruit, such as grape (Vitis sp.) (Botta et al., 1995; Lamboy and Alpha, 1998), tea crabapples (Malus hupehen-

Table 1. SSR variability measures for 48 kiwifruit cultivars and selections. Ploidy level for the cultivars and selections listed are based on data available from the computer database of Actinidia research center, WIB.

\begin{tabular}{|c|c|c|c|c|}
\hline Cultivar or selection & Origin & $\mathrm{A}^{\mathrm{z}}$ & $\mathrm{P}^{\mathrm{Y}}$ & $\mathrm{H}_{\mathrm{o}}^{\mathrm{X}}$ \\
\hline \multicolumn{5}{|l|}{ A. chinensis } \\
\hline Kuimi (4x) & $\begin{array}{l}\text { Wild selection from Fengxin Co., } \\
\text { Jiangxi province }(\mathrm{Jx})\end{array}$ & 2.9 & 100 & 0.630 \\
\hline Zaoxian $(4 x)$ & $\begin{array}{l}\text { Wild selection from Fengxin Co., } \\
\text { Jiangxi province }\left(\mathrm{Jx}_{\mathrm{x}}\right)\end{array}$ & 2.7 & 100 & 0.602 \\
\hline Jinfeng $(4 x)$ & $\begin{array}{l}\text { Wild selection from Fengxin Co., } \\
\text { Jiangxi province }(\mathrm{Jx})\end{array}$ & 3.0 & 87.5 & 0.594 \\
\hline Yixiang $(4 x)$ & $\begin{array}{l}\text { Wild selection from Xuishui Co., } \\
\text { Jiangxi province }(\mathrm{Jx})\end{array}$ & 2.7 & 88.9 & 0.556 \\
\hline Jiangyuan-1 (4x) & $\begin{array}{l}\text { Wild selection from Jiangxi } \\
\text { province }(\mathrm{Jx})\end{array}$ & 3.1 & 100 & 0.659 \\
\hline Wuzhi-2 (4x) & $\begin{array}{l}\text { Wild selection from Wuning Co., } \\
\text { Jiangxi province }\left(\mathrm{J}_{\mathrm{X}}\right)\end{array}$ & 3.1 & 100 & 0.676 \\
\hline Wuzhi-3 (4x) & $\begin{array}{l}\text { Wild selection from Wuning Co., } \\
\text { Jiangxi province }(\mathrm{Jx})\end{array}$ & 3.0 & 100 & 0.639 \\
\hline Wuzhi-5 (4x) & $\begin{array}{l}\text { Wild selection from Wuning Co., } \\
\text { Jiangxi province }(\mathrm{Jx})\end{array}$ & 3.0 & 100 & 0.639 \\
\hline Wuzhi-6 (4x) & $\begin{array}{l}\text { Wild selection from Wuning Co., } \\
\text { Jiangxi province }(\mathrm{Jx})\end{array}$ & 2.9 & 88.9 & 0.630 \\
\hline Tongshan-5 (4x) & $\begin{array}{l}\text { Wild selection from Tongshan Co., } \\
\text { Hubei province (Hub) }\end{array}$ & 3.0 & 100 & 0.648 \\
\hline Jinyang $(4 x)$ & $\begin{array}{l}\text { Wild selection from Chongyang Co., } \\
\text { Hubei province (Hub) }\end{array}$ & 2.5 & 100 & 0.573 \\
\hline Jinnong-1 $(2 x)$ & $\begin{array}{l}\text { Seedling selected from mixed seeds collected } \\
\text { from wild at Fang Co., Hubei Province (Hub) }\end{array}$ & 1.8 & 66.7 & 0.333 \\
\hline Jinshui-1-111 (2x) & $\begin{array}{l}\text { Seedling selected from mixed seeds collected } \\
\text { from wild at Fang Co., Hubei Province (Hub) }\end{array}$ & 1.6 & 55.6 & 0.278 \\
\hline Luoyang-1 (4x) & $\begin{array}{l}\text { Wild selection from Song Co., } \\
\text { Henan Province (Hen) }\end{array}$ & 3.1 & 100 & 0.676 \\
\hline Huaguang-3 (4x) & $\begin{array}{l}\text { Wild selection from Funiu Mt., } \\
\text { Henan Province (Hen) }\end{array}$ & 2.7 & 88.9 & 0.521 \\
\hline Funiuhongrou ( $4 x)$ & $\begin{array}{l}\text { Wild selection from Funiu Mt., } \\
\text { Henan Province (Hen) }\end{array}$ & 2.8 & 77.8 & 0.509 \\
\hline Chuanmi-3 & $\begin{array}{l}\text { Wild selection from Henan } \\
\text { Province (Hen) }\end{array}$ & 1.9 & 85.7 & 0.429 \\
\hline Chuanmi-4 & $\begin{array}{l}\text { Wild selection from Henan } \\
\text { Province (Hen) }\end{array}$ & 2.3 & 100 & 0.546 \\
\hline Xiangma-6 & $\begin{array}{l}\text { Wild selection from Mayang Co., } \\
\text { Hunan Province (Hun) }\end{array}$ & 2.3 & 77.8 & 0.472 \\
\hline Jianke-1 & $\begin{array}{l}\text { Wild selection from Jianning Co., } \\
\text { Fujian Province }(\mathrm{Fj})\end{array}$ & 2.6 & 77.8 & 0.500 \\
\hline Xiaya-1 $(4 x)$ & $\begin{array}{l}\text { Wild selection from Fujian } \\
\text { Province }(F j)\end{array}$ & 2.8 & 100 & 0.615 \\
\hline Xiaya-15 (4x) & $\begin{array}{l}\text { Wild selection from Fujian } \\
\text { Province }(F j)\end{array}$ & 3.0 & 100 & 0.630 \\
\hline Guihai-4 (2x) & $\begin{array}{l}\text { Wild selection from Longsheng Co., } \\
\text { Guangxi Province }(\mathrm{Gx})\end{array}$ & 1.8 & 66.7 & 0.333 \\
\hline Hongyang $(2 x)$ & $\begin{array}{l}\text { Wild selection from Sichuan } \\
\text { Province }(\mathrm{Sc})\end{array}$ & 1.7 & 62.5 & 0.313 \\
\hline Qingyuanqiucui & $\begin{array}{l}\text { Wild selection from Qingyuan Co., } \\
\text { Zhejiang Province }(\mathrm{Zj})\end{array}$ & 3.1 & 100 & 0.658 \\
\hline
\end{tabular}


sis (Damp.) Rehd.) (Benson et al., 2001; Hokanson et al., 1998), Citrus (Gulsen and Roose, 2001), and sour cherry (Prunus cerasus L.) (Cantini et al., 2001). More than 40 SSRs from kiwifruit have been developed and about 20 SSRs were verified as single Mendelian loci in intra- and interspecific crossed families (Huang et al., 1998; Weising et al., 1996). The emergence of PCR-based molecular markers has provided the opportunity for a wide array of investigations in Actinidia, such as RAPD markers for cultivar fingerprinting and taxonomical relationships (Cipriani et al., 1996;
Huang et al., 2002), PCR-RFLPs of cpDNA and mtDNA for studying cytoplasmically genetic phylogeny (Chat et al., 1999; Cipriani et al., 1995; Testolin and Cipriani 1997), and combination of RAPD markers and SSRs for verifying somaclonal variation in tissue cultures (Palombi and Damiano 2002). However, SSRs for fingerprinting kiwifruit cultivars and germplasm accessions has not been explored probably because most newly developed cultivars and selections are restricted to China. Therefore, in the present study, we employed a set of nine genetically defined

Table 1 (continued). SSR variability measures for 48 kiwifruit cultivars and selections. Ploidy level for the cultivars and selections listed are based on data available from the computer database of Actinidia research center, WIB.

\begin{tabular}{|c|c|c|c|c|}
\hline Cultivar or selection & Origin & $\mathrm{A}^{\mathrm{Z}}$ & $\overline{\mathrm{P}^{\mathrm{Y}}}$ & $\mathrm{H}_{\mathrm{o}}^{\mathrm{X}}$ \\
\hline Earligold $(2 x)$ & $\begin{array}{l}\text { Seedling selection from a second } \\
\text { generation of mixed open-pollinated seeds by } \\
\text { HortResearch, New Zealand }\end{array}$ & 1.9 & 88.9 & 0.444 \\
\hline Mean (A. chinesis) & & 2.6 & 89.4 & 0.546 \\
\hline \multicolumn{5}{|c|}{ A. deliciosa (all genotypes are $6 x$ ) } \\
\hline Qinmei & $\begin{array}{l}\text { Wild selection from Zhouzhi Co., } \\
\text { Shaanxi Province (Shaax) }\end{array}$ & 3.6 & 100 & 0.704 \\
\hline Yate & $\begin{array}{l}\text { Wild selection from Hu Co., } \\
\text { Shaanxi Province (Shaax) }\end{array}$ & 3.7 & 100 & 0.709 \\
\hline Xixuan-1 & $\begin{array}{l}\text { Wild selection from Shaanxi } \\
\text { Province (Shaax) }\end{array}$ & 3.0 & 87.5 & 0.579 \\
\hline Changan-1 & $\begin{array}{l}\text { Wild selection from Changan Co., } \\
\text { Shaanxi Province (Shaax) }\end{array}$ & 3.3 & 77.8 & 0.520 \\
\hline Miliang-1 & $\begin{array}{l}\text { Wild selection from Fenghuang Co., } \\
\text { Hunan Province (Hun) }\end{array}$ & 4.1 & 100 & 0.752 \\
\hline Dongshanfeng & $\begin{array}{l}\text { Wild selection from Dongshan Mt., } \\
\text { Hunan Province (Hun) }\end{array}$ & 3.4 & 100 & 0.669 \\
\hline Jinkui & $\begin{array}{l}\text { Seedling selected from wild selection } \\
\text { Zhuxi-4 at Zhuxi Co., Hubei Province (Hub) }\end{array}$ & 3.8 & 100 & 0.702 \\
\hline Qingcui & $\begin{array}{l}\text { Wild selection from Dujiangyan Co., } \\
\text { Sichuan Province }(\mathrm{Sc})\end{array}$ & 2.9 & 77.8 & 0.502 \\
\hline Xinguan-2 & $\begin{array}{l}\text { Wild selection from Cangxi Co., } \\
\text { Sichuan Province }(\mathrm{Sc})\end{array}$ & 2.6 & 100 & 0.594 \\
\hline Lushanmei & $\begin{array}{l}\text { Wild selection from Jiangxi } \\
\text { Province }(\mathrm{Jx})\end{array}$ & 3.8 & 100 & 0.719 \\
\hline Huamei-1 & $\begin{array}{l}\text { Wild selection from Funiu Mt., } \\
\text { Henan Province (Hen) }\end{array}$ & 3.9 & 100 & 0.721 \\
\hline Chuanmi-1 & $\begin{array}{l}\text { Wild selection from Henan } \\
\text { Province (Hen) }\end{array}$ & 2.8 & 100 & 0.621 \\
\hline Chuanmi-2 & $\begin{array}{l}\text { Wild selection from Henan } \\
\text { Province (Hen) }\end{array}$ & 3.2 & 100 & 0.667 \\
\hline Hayward & $\begin{array}{l}\text { Seedling selection by New Zealand growers } \\
\text { from mixed seeds collected at Yichang, Hubei }\end{array}$ & 3.9 & 100 & 0.735 \\
\hline Bruno & $\begin{array}{l}\text { Seedling selection by New Zealand growers } \\
\text { from mixed seeds collected at Yichang, Hubei }\end{array}$ & 4.0 & 100 & 0.720 \\
\hline Xianglv & Open-pollinated seedling of Hayward & 4.1 & 100 & 0.748 \\
\hline Xuxiang & Open-pollinated seedling of Hayward & 3.5 & 100 & 0.704 \\
\hline Xuguan & Open-pollinated seedling of Hayward & 3.4 & 100 & 0.691 \\
\hline Shixuan-3 & Open-pollinated seedling of Hayward & 3.4 & 100 & 0.691 \\
\hline Mean (A. deliciosa) & & 3.5 & 97.0 & 0.671 \\
\hline \multicolumn{5}{|c|}{ Interspecific hybrid (A. chinensis $\mathrm{x}$ A. eriantha) } \\
\hline Mantianxing & Wuzhi-3 x EA1998YN & 2.8 & 100 & 0.630 \\
\hline Jiangshanjiao & Wuzhi-3 x EA1998YN & 2.3 & 100 & 0.548 \\
\hline Mean (hybrids) & & 2.6 & 100 & 0.589 \\
\hline \multicolumn{5}{|l|}{ A. arguta } \\
\hline Kuilv $(2 x)$ & $\begin{array}{l}\text { Wild selection from Jian Co., } \\
\text { Jilin province }(\mathrm{J} 1)\end{array}$ & 1.8 & 66.7 & 0.361 \\
\hline
\end{tabular}

zNumber of alleles per locus.

yPercentage of polymorphic loci. 
Table 2. Distribution of allelic frequencies and number of alleles in 48 kiwifruit genotypes.

\begin{tabular}{lcc}
\hline $\begin{array}{l}\text { Allelic } \\
\text { frequency range }\end{array}$ & $\begin{array}{l}\text { No. of } \\
\text { alleles }\end{array}$ & Percentage \\
\hline$>0.1000$ & 11 & 5.2 \\
$0.1000-0.0749$ & 15 & 7.0 \\
$0.0750-0.0499$ & 34 & 16.0 \\
$0.0500-0.0249$ & 72 & 33.8 \\
$0.0250-0.0099$ & 47 & 22.0 \\
$<0.0100$ & 34 & 16.0 \\
\hline
\end{tabular}

SSR markers developed at University of Udine (Huang et al., 1998) to fingerprint kiwifruit cultivars and selections and assess the genetic diversity and relatedness of cultivars and selections developed from two commercially important species, A. deliciosa and A. chinensis.

\section{Materials and Methods}

Genomic DNA was isolated from approximately $2 \mathrm{~g}$ leaf tissue from 48 cultivars and selections (Table 1) using a modified cetyltrimethylammonium bromide (CTAB)-based procedure outlined in Wagner et al. (1987). They included 26 cultivars and selections of A. chinensis, 19 of A. deliciosa, one of A. arguta, and two interspecific hybrids, which account for more than $90 \%$ of total world kiwifruit production (Huang and Ferguson, 2001). These cultivars and selections were maintained as field collections at the national germplasm repository for Actinidia at WIB, Wuhan, Hubei province, P.R. China. The RNAcomponent of these individual extracts was removed by incubation in the presence of RNase A as described in Ausubel et al. (1987). DNA at100 ng/ $\mu \mathrm{L}$ was used as template for PCR amplification. Sixteen SSR primer pairs (Huang et al., 1998) were used for initial screening against 10 cultivars each of $A$. deliciosa and $A$. chinensis for reproducibility and intensity of DNA fragments. Nine SSR primer pairs were then chosen for genotyping the remainder of cultivars and selections. DNA amplifications were performed using a protocol described by Huang et al. (1998). The reaction consisted of the following in $25 \mu \mathrm{L}$ total volume: $100 \mathrm{ng}$ of template DNA, $10 \mathrm{~mm}$ Tris- $\mathrm{HCl}$ ( $\mathrm{pH} 9.0$ ), $50 \mathrm{~mm} \mathrm{KCl,} 1.5 \mathrm{~mm} \mathrm{MgCl}_{2}, 0.2 \mathrm{~mm}$ of each $\mathrm{dNTP}, 0.2 \mu \mathrm{M}$ of each primer, and $0.4 \mathrm{U}$ of Taq DNA polymerase (Promega). The DNA samples were amplified using the following thermal profile: $5 \mathrm{~min}$ at $95^{\circ} \mathrm{C}$; followed by 35 cycles of 50 $\mathrm{s}$ at $94^{\circ} \mathrm{C}, 50 \mathrm{~s}$ at $55^{\circ} \mathrm{C}$ and $50 \mathrm{~s}$ at $72{ }^{\circ} \mathrm{C}$; followed by $8 \mathrm{~min}$ at $72{ }^{\circ} \mathrm{C}$. The amplification products were electrophoresed in $8 \%$ polyacrylamide denaturing gels using a Sequi-Gen GT/Power Pac 3000 Sequencer System (Bio-Rad) for approximately $1.5 \mathrm{~h}$ at 55 $\mathrm{W}$, followed by silver staining (Promega, Madison, Wis.). Each sample/primer combination was amplified at least three times to verify reproducibility. The bands of amplified DNA fragments were manually scored and pBR322 DNA/Msp I ladder(Sino-American Biotechnology Company, China) was used to determine the size of amplified DNA fragments.

SSR markers were designated by the manufacturer primer code (referred to as locus) corresponding to the primer pair sequences responsible for their amplification, followed by a digital number indicating the product size in base pairs referred to as alleles. Number of alleles per locus (A), percentage of polymorphic loci $(\mathrm{P})$, direct count heterozygosity $\left(\mathrm{H}_{\mathrm{o}}\right)$ and genetic diversity were calculated according Weir (1996). When a cultivar showed one fragment (allele) at a locus, it was considered to be homozygous at the locus. In cases when a cultivar was actually heterozygous for one allele and a null allele, the results reported herein underestimate the level of heterozygosity and the mean heterozygosity estimated may also include inter-locus heterozygosity because duplicate loci could occur in both $A$. deliciosa (hexaploid) and $A$. chinensis (includes diploid and tetraploid races), as well as in the interspecific hybrids (Caniti et al., 2001; Hokanson et al., 1998). The ploidy level of most cultivars and selections was previously determined (WIB Actinidia database, unpublished). The relative magnitude of genetic differentiation between $A$. chinensis and $A$. deliciosa cultivar groups $\left(\mathrm{G}_{\mathrm{st}}=\mathrm{D}_{\mathrm{st}} / \mathrm{H}_{\mathrm{T}},(\mathrm{Nei}, 1978)\right)$ was calculated by different methods implemented in AMOVA (http: //acasun1.unige.ch/LGB/software/windoze/amova) and Microsat (http://hpg1.stanford.edu/projects/microsat/) software.

For the purpose of examining the genetic relationships among the 48 cultivars and selections, allelic data were treated in binary format and scored as 1 (band present) or 0 (band absent), and were referred to as allelic phenotypes. Dice (1945) coefficients, which are equivalent to Nei and Li (1979) genetic identities, were calculated for all possible pairwise combinations of kiwifruit genotypes. A dendrogram was constructed based on the matrix of the Dice coefficients by unweighted pair-group mean analysis (UPGMA) using the software NTSYS-pc v.1.8 (Exeter Software, Setauket, N.Y.).

\section{Results}

SSR POLYMORPHISM AND GENETIC DIVERSITY. All nine SSR markers employed for characterization of the 48 kiwifruit genotypes were polymophic. Six and four alleles were the maximum number of alleles observed in A. deliciosa $(2 n=6 x)$ and A. chinensis $(2 n$ $=2 x$ and $4 x$ ) genotypes, respectively. Because the ploidy level of most cultivars and selections were previously known, this provided a crosscheck for accuracy of scoring alleles. In total, 213 alleles were detected, giving a mean number of 23.7 alleles per locus (A) ranging from nine alleles in UDK97-409 to 38 alleles in UDK96026 . Only $5.16 \%$ of the alleles had frequencies $>0.1000$ (Table 2 ). Nineteen homozygous null alleles were detected in a total of 432 combinations of 48 genotypes by nine loci (Table 3 ). Of the 213 alleles, two alleles were found to be specific to 'Kuilv' of $A$. arguta and 'Jiangshanjiao', an interspecific hybrid. Interestingly, 133 alleles were found to be common to both $A$. chinensis and $A$. deliciosa, while 33 and 36 alleles were specific to A. chinensis and $A$. deliciosa, respectively. In addition, 34 alleles were found to be specific to one single cultivar or selection and provided a valuable set of alleles to enhance the discrimination ability for cultivar identification (Table 3). Gene diversity measured for each locus ranged from 0.73 for UDK97-409 to 0.96 for both UDK96-026 and UDK96-414, with an average gene diversity value of 0.92 for all loci obtained after pooling all cultivars and selections from both $A$. chinensis and A. deliciosa. When gene diversity was calculated across all loci for comparison between $A$. deliciosa and $A$. chinensis cultivar groups, mean gene diversity of A. deliciosa was slightly higher than that of $A$. chinensis (0.91 vs. 0.89).

The mean number of alleles per locus (A), percentage of polymorphic loci $(\mathrm{P})$ and direct count heterozygosity $\left(\mathrm{H}_{\mathrm{o}}\right)$ assessed for each genotype over all loci revealed differences among these 48 cultivars and selections. On average, $\mathrm{A}=2.6, \mathrm{P}=89.4 \%$ and $\mathrm{H}_{\mathrm{o}}=0.546$ were found in $A$. chinensis genotypes, while $\mathrm{A}=3.5$, $\mathrm{P}=97.0 \%$ and $\mathrm{H}_{\mathrm{o}}=0.671$ in $A$. deliciosa genotypes. The highest direct count heterozygosity of 0.752 was observed in the $A$. 
deliciosa cultivar, Miliang-1, and the lowest of 0.278 in a diploid A. chinensis selection 'Jinshui 1-111'. Similarly, the diploid A. arguta cultivar, Kuilv, was also found to be one of the lowest $\mathrm{H}_{\mathrm{o}}$ (0.361) (Table 1).

SSR FINGERPRINTING KIWIFRUIT CULTIVARS AND SELECTIONS. All 48 kiwifruit genotypes were uniquely identified by one locus, UDK96-414, except two genotypes, 'Xiaya-1' and 'Xiaya-15', which were presumably selected from the same wild parent vine
(Zhang, personal communication) and showed the same allelic composition at eight loci (Table 3 ). However, 'Xiaya-1' revealed a homozygous null allele at locus UDK96-026-0/0/0/0 that was distinctly different from 'Xiaya-15', which revealed a tetra-allelic composition of UDK96-026-217/211/201/117 (Table 3). The UDK96-026 and UDK 96-414 are the most hypervariable loci, with 38 and 32 alleles detected, respectively. This suggests a possibility that somaclonal variability occurs and agrees with

Table 3. The SSR fingerprinting of kiwifruit cultivars and selections.

\begin{tabular}{|c|c|c|c|c|}
\hline \multirow[b]{2}{*}{ Cultivars } & \multicolumn{4}{|c|}{ Locus code } \\
\hline & UDK 96-001 & UDK 96-015 & UDK 96-016 & UDK 96-030 \\
\hline$\overline{\text { Wuzhi-3 }}$ & $272 / 238$ & $141 / 127$ & $223 / 211 / 199$ & $201 / 181 / 141 / 127$ \\
\hline Wuzhi-5 & $286 / 276 / 272 / 256$ & $133 / 131 / 127$ & $211 / 199$ & $165 / 157 / 141$ \\
\hline Wuzhi-6 & $282 / 266 / 264$ & $151 / 145 / 137 / 127$ & $207 / 201$ & $165 / 141 / 119$ \\
\hline Miliang-1 & $282 / 276 / 264 / 246 / 238$ & $145 / 141 / 137 / 133 / 127$ & $253 / 223 / 201 / 197$ & $165 / 141 / 135 / 115^{*}$ \\
\hline Tongshan-5 & $272 / 252$ & $129 / 127$ & $223 / 211 / 207 / 201$ & $193 / 183 / 141$ \\
\hline Jinnong-1 & 264 & $137 / 133$ & 203 & $123 / 119 / 111$ \\
\hline Wuzhi-2 & $282 / 276 / 238$ & $167 / 141 / 127$ & $215 / 207 / 201$ & $181 / 165 / 141 / 119$ \\
\hline Jinyang & $272 / 256$ & $141 / 127$ & 223/203/199 & $205 / 145$ \\
\hline Jinshui-1-111 & 280 & 141 & $207 / 203$ & $147 / 123$ \\
\hline Kuimi & $282 / 280 / 264$ & $133 / 127 / 121$ & $223 / 215 / 207 / 203$ & $145 / 131 / 123$ \\
\hline Jinfeng & $280 / 272 / 266 / 248$ & Null allele & $223 / 207 / 201 / 195$ & $157 / 149 / 131$ \\
\hline Xinguan-2 & $282 / 268 / 264$ & $137 / 129$ & $221 / 215 / 201$ & $161 / 147 / 139 / 131$ \\
\hline Zaoxian & $290 / 268 / 248$ & $159 / 141 / 123$ & $223 / 215 / 207 / 201$ & $187 * / 157 / 149$ \\
\hline Lushanmei & $276 / 268 / 264 / 248$ & $151 / 137 / 133 / 127$ & $253 / 227 / 211 / 207 / 201$ & 201/165/157/141 \\
\hline Huaguang-3 & $272 / 264$ & $137 / 123$ & $201 / 195$ & $231 / 181 / 157 / 141$ \\
\hline Shixuan-3 & $272 / 256 / 248$ & $151 / 137 / 133 / 131 / 127$ & $207 / 205 / 201$ & $161 / 141 / 137$ \\
\hline Funiuhongrou & $280 / 272 / 266$ & $145 / 127$ & $213 / 201 / 195$ & 151 \\
\hline Luoyang-1 & $282 / 280 / 260$ & $133 / 127 / 123$ & $227 / 215 / 207 / 203$ & $145 / 131 / 123$ \\
\hline Dongshanfeng & $272 / 268 / 264$ & $145 / 133 / 125$ & $249 * / 227 / 211 / 203 / 191 *$ & $149 / 141 / 139$ \\
\hline Huamei-1 & $286 / 270 / 248 / 242$ & $163 / 151 / 141 / 133 / 121$ & $253 / 227 / 213 / 207 / 203$ & $201 / 161 / 133 / 123$ \\
\hline Xianglv & $270 / 248 / 238$ & $151 / 145 / 141 / 127$ & $253 / 227 / 213 / 207 / 203$ & $183 / 165 / 123 / 113 * / 107$ \\
\hline Hongyang & 280 & 141 & $207 / 201$ & $145 / 125 *$ \\
\hline Xiaya-15 & $276 / 268 / 246$ & $163 / 141 / 127$ & $205 / 201$ & $155 / 119$ \\
\hline Xixuan-1 & $276 / 260 / 252$ & $141 / 127$ & $229 / 223 / 211 / 209$ & $153 / 141 / 139$ \\
\hline Chang'an-1 & $290 / 282 / 280 / 260 / 242$ & $141 / 135$ & $213 / 195$ & 205/141/131/123/119 \\
\hline Xiaya-1 & $276 / 268 / 246$ & $163 / 141 / 127$ & $205 / 201$ & $155 / 119$ \\
\hline Xiangma-6 & $296 / 286 / 282 / 276$ & $145 / 141$ & 203/199 & $153 / 137$ \\
\hline Yate & $290 / 280 / 272$ & $145 / 141 / 127$ & $207 / 203$ & $157 / 155 / 147 / 135$ \\
\hline Xuguan & $272 / 256$ & $151 / 135 / 131 / 127$ & $257 / 207 / 201$ & $231 / 147 / 135 / 119 / 111$ \\
\hline Xuxiang & $290 / 272 / 268 / 256$ & Null allele & $229 / 207 / 195$ & $217 * / 165 / 151 / 145 / 127$ \\
\hline Chuanmi-1 & $272 / 268$ & $159 / 145 / 131$ & $251 * / 221 / 209$ & $157 / 149 / 119$ \\
\hline Bruno & $268 / 248 / 238$ & $151 / 145 / 141 / 131 / 127$ & $257 / 229 / 207 / 205$ & $231 / 155 / 145 / 131 / 123 / 107$ \\
\hline Guihai-4 & 296 & $145 / 121$ & $211 / 203$ & 147 \\
\hline Chuanmi-2 & $280 / 270$ & $151 / 141 / 127 / 115^{*}$ & $221 / 209 / 205 / 199$ & 161/135/131/111 \\
\hline Chuanmi-3 & $286 / 260$ & $175 / 145$ & $205 / 199$ & $183 / 111$ \\
\hline Jinkui & Null allele & $175 / 155 * / 151 / 135 / 129 / 123$ & $209 / 205$ & $161 / 141 / 131 / 105$ \\
\hline Hayward & $272 / 266 / 248 / 246$ & $141 / 127$ & $253 / 227 / 207 / 203$ & $183 / 161 / 147 / 131$ \\
\hline Qinmei & $272 / 268 / 246 / 238$ & $131 / 121$ & $227 / 207 / 203$ & $157 / 149 / 139 / 133$ \\
\hline Qingyuanqiucui & $282 / 272 / 252$ & $129 / 127 / 121 / 109$ & 209/203/199 & $165 / 157 / 139$ \\
\hline Kuilv & $272 / 260$ & Null allele & 199 & $107 / 105$ \\
\hline Yixiang & $272 / 260$ & $151 / 135$ & $223 / 211 / 205 / 199$ & $193 / 183 / 157 / 135$ \\
\hline Jiangyuan-1 & Null allele & $159 / 131 / 129 / 121$ & $205 / 197$ & $161 / 141 / 139 / 119$ \\
\hline Jianke-1 & 264 & $135 / 131$ & $213 / 207 / 199$ & $127 / 111$ \\
\hline Qingcui & $282 / 268$ & $135 / 125$ & $221 / 211 / 201 / 195$ & 141 \\
\hline Chuanmi-4 & $272 / 264$ & $167 / 145$ & $209 / 201$ & $181 / 173$ \\
\hline Jiangshanjiao & Null allele & $141 / 109$ & Null allele & $173 / 141$ \\
\hline Mantianxing & $266 / 256 / 242$ & $121 / 109$ & $223 / 211 / 199$ & $201 / 165 / 127$ \\
\hline Earligold & 282 & $131 / 123$ & $211 / 205$ & $183 / 131$ \\
\hline
\end{tabular}

"Allele specific to the cultivar. 
results on detection of somaclonal variation by SSR markers (Palombi and Damiano, 2002).

Genetic RELATEDNESS. The genetic identity, as measured by Dice coefficient, varies from 0.03 to 0.80 among the cultivars and selections, with the highest identity (0.80) observed between 'Xiaya-1' and 'Xiaya-15' and the smallest (0.03) observed between 'Kuilv' of $A$. arguta and other cultivars of $A$. chinensis and $A$. deliciosa. The genetic relationships among the cultivars and advanced selections were examined by UPGMAcluster analysis, as presented in Fig. 1. This dendrogram is a representation of apparent genetic similarity and it is not a pedigree or family tree. The high correlation coefficient $(r=0.95)$, as calculated by MIXCOMP program in NTSYS, indicated "the goodness of fit" of this SSR dendrogram. In order to examine genetic relationships among the taxa, a cut-off point $\left(\mathrm{D}_{1}=0.09\right)$ was determined according to $\mathrm{Xu}$ and Li's (1983) method of grouping taxa. The dendrogram, in general, separated 48 cultivars and selections into four clusters and one individual cultivar (Fig. 1). Cluster I consisted of mixed

\begin{tabular}{|c|c|c|c|c|}
\hline \multicolumn{5}{|c|}{ Locus code } \\
\hline UDK 96-034 & UDK 96-040 & UDK96-026 & UDK97-409 & UDK 97-414 \\
\hline $202 / 188$ & $190 / 180 * / 156 / 124$ & $207 / 195 / 187 / 107$ & $240 / 146 / 130$ & $177 / 107 / 95$ \\
\hline $188 / 184$ & $188 / 170 / 136 / 124$ & $187 / 157 / 117 / 107$ & $240 / 130$ & $153 / 127 / 103$ \\
\hline $188 / 184$ & $188 / 166 / 150 / 116$ & 191/181/153/107 & $240 / 130$ & 107 \\
\hline $218 / 212 / 204 / 186$ & $162 / 154 / 140$ & $195 / 167 / 133 / 113$ & $240 / 190 / 146 / 130$ & $123 / 107 / 101 * / 95$ \\
\hline $202 / 194 / 188$ & $170 / 156 / 154 / 144$ & 205/193/181 & $240 / 146 / 130$ & $153 / 133 / 107$ \\
\hline $216 / 212$ & $128 / 116$ & $213 * / 191$ & $240 / 130$ & $127 / 97$ \\
\hline $216 / 200 / 184$ & $168 / 124 / 116$ & $205 / 187 / 173^{*}$ & $240 / 132 * / 130$ & $137 / 107 / 97$ \\
\hline Null allele & $166 / 116$ & $209 * / 205 / 193 / 181$ & $240 / 130$ & $157 / 127 / 107$ \\
\hline $196 / 172$ & 116 & $187 / 153$ & 240 & $181 / 157$ \\
\hline 200/194/188/186 & $166 / 124$ & $201 / 183$ & $240 / 130$ & $153 / 133 / 99$ \\
\hline 202/194/172 & $166 / 154$ & 205/201/139/111 & 240 & $133 / 107 / 99$ \\
\hline $196 / 186$ & $168 / 154 / 124$ & $157 / 103$ & $240 / 130$ & $157 / 133 / 99$ \\
\hline $200 / 182$ & $170 / 116$ & 205/139/119 & $240 / 130$ & $181 / 153$ \\
\hline $212 / 208 / 182 / 174 * / 168 *$ & $166 / 156 / 140 / 136$ & 205/197/139/119 & $240 / 130$ & $131 / 123 / 111$ \\
\hline $202 / 176$ & $166 / 124$ & $205 / 193 / 117$ & 240 & $193 * / 165 / 107 / 93 *$ \\
\hline $218 / 202$ & $170 / 156 / 154 / 144$ & $197 / 139 / 119$ & $240 / 232 / 146 / 130$ & $179 / 161 / 111 / 95$ \\
\hline $212 / 208 / 196 / 184$ & $160 / 156 / 124$ & $205 / 139 / 119$ & 240 & $177 / 153 / 141$ \\
\hline $196 / 194 / 188 / 186$ & $168 / 166 / 124$ & $205 / 185 / 105$ & $240 / 130$ & $157 / 137 / 103$ \\
\hline $204 / 196$ & $170 / 168 / 140 / 136$ & $157 / 103$ & $240 / 146 / 130$ & $169 / 145 / 127 / 107 / 95$ \\
\hline $200 / 178$ & $188 / 166 / 136 / 124$ & $195 / 161 * / 111$ & Null allele & $179 / 149 / 127 / 97$ \\
\hline $218 / 202 / 172$ & $160 / 156 / 140 / 124$ & $195 / 159 * / 111 / 109 / 103$ & $240 / 232 / 226 / 130$ & $169 / 157 / 113 / 97$ \\
\hline 196 & $144 / 136$ & $193 / 185$ & Null allele & $153 / 133$ \\
\hline $206 / 196 / 176$ & $160 / 154 / 124 / 116$ & $217 * / 211 / 201 / 117$ & $240 / 130$ & $183 / 121 / 99$ \\
\hline $206 / 180$ & $170 / 166 / 150 / 124$ & Null allele & $240 / 226 / 190 / 174 / 130$ & 133 \\
\hline 180 & $170 / 148 / 132 / 124$ & 205 & $240 / 232 / 130$ & $149 / 127 / 113$ \\
\hline $206 / 196 / 176$ & $160 / 154 / 124 / 116$ & Null allele & $240 / 130$ & $183 / 121 / 99$ \\
\hline 186 & $162 / 150 / 140$ & $195 / 167 / 113$ & 240 & $147 * / 137 / 99$ \\
\hline $220 * / 206 / 200 / 186$ & $156 / 150 / 144 / 124$ & 205/181/139/119 & $240 / 232 / 174 / 146 / 130$ & $169 / 149 / 133 / 103$ \\
\hline $216 / 204 / 182$ & $156 / 154 / 128 / 116$ & $203 * / 189 / 157$ & $240 / 232 / 146 / 130$ & $161 / 111 / 95$ \\
\hline $196 / 178 / 172$ & $166 / 156 / 124$ & $201 / 133 / 117$ & $240 / 174 / 130$ & $177 / 145 / 127 / 111$ \\
\hline $210 / 206$ & $166 / 128$ & $211 / 197 / 185$ & $240 / 146 / 130$ & $177 / 145 / 121 / 95$ \\
\hline $216 / 172$ & $170 / 156 / 154 / 140 / 128$ & 205/191/133/119/109 & $240 / 232 / 130$ & $177 / 161 / 123$ \\
\hline $204 / 186$ & $144 / 128$ & $139 / 119$ & 240 & $161 / 131$ \\
\hline $180 / 176$ & $170 / 162 / 160 / 132$ & $201 / 133 / 113$ & $240 / 232 / 130$ & $161 / 131 / 103$ \\
\hline $200 / 196$ & 154 & Null allele & Null allele & $177 / 153$ \\
\hline $216 / 210 / 200$ & $188 / 170 / 156 / 128$ & $205 / 133 / 111$ & Null allele & $169 / 145 / 103 / 97$ \\
\hline $202 / 190 / 180$ & $170 / 160 / 156 / 154 / 124$ & $205 / 187 / 133 / 113 / 103$ & $240 / 226 / 146 / 130$ & $177 / 153 / 123 / 103$ \\
\hline $196 / 186 / 184$ & $170 / 160 / 154 / 124$ & Null allele & $240 / 226 / 190 / 174 / 130$ & $121 / 113 / 107 / 89^{*}$ \\
\hline $202 / 176$ & $188 / 170 / 136 / 124$ & $201 / 185 / 113 / 103$ & $240 / 130$ & $153 / 123 / 99$ \\
\hline 190 & $148 / 132 / 110 *$ & $207 / 199$ & Null allele & Null allele \\
\hline $190 / 186$ & $170 / 156 / 154$ & $179 *$ & $240 / 146 / 130$ & $145 / 123 / 103$ \\
\hline Null allele & $190 / 168 / 144$ & $199 / 181 / 113 / 101 *$ & $240 / 174$ & $145 / 123 / 99$ \\
\hline $210 / 200 / 190 / 184$ & $170 / 168 / 160$ & $193 / 153 / 123 * / 109$ & 240 & $183 / 127 / 121$ \\
\hline 182 & $170 / 166 / 156 / 140 / 128$ & $187 / 183 / 127 * / 113 / 109$ & $240 / 174$ & $177 / 141 / 121$ \\
\hline $190 / 160$ & $154 / 140$ & $189 / 185 / 105$ & $240 / 130$ & $185^{* / 173 * / 141 / 123}$ \\
\hline $184 / 172$ & $166 / 150$ & $191 / 173$ & $240 / 168 * / 130$ & $141 / 127 / 103$ \\
\hline $216 / 160$ & $170 / 156 / 150$ & $187 / 157 / 107$ & $240 / 146 / 130$ & $177 / 141 / 127$ \\
\hline $190 / 184$ & $140 / 116$ & $189 / 181$ & $240 / 130$ & $165 / 121$ \\
\hline
\end{tabular}




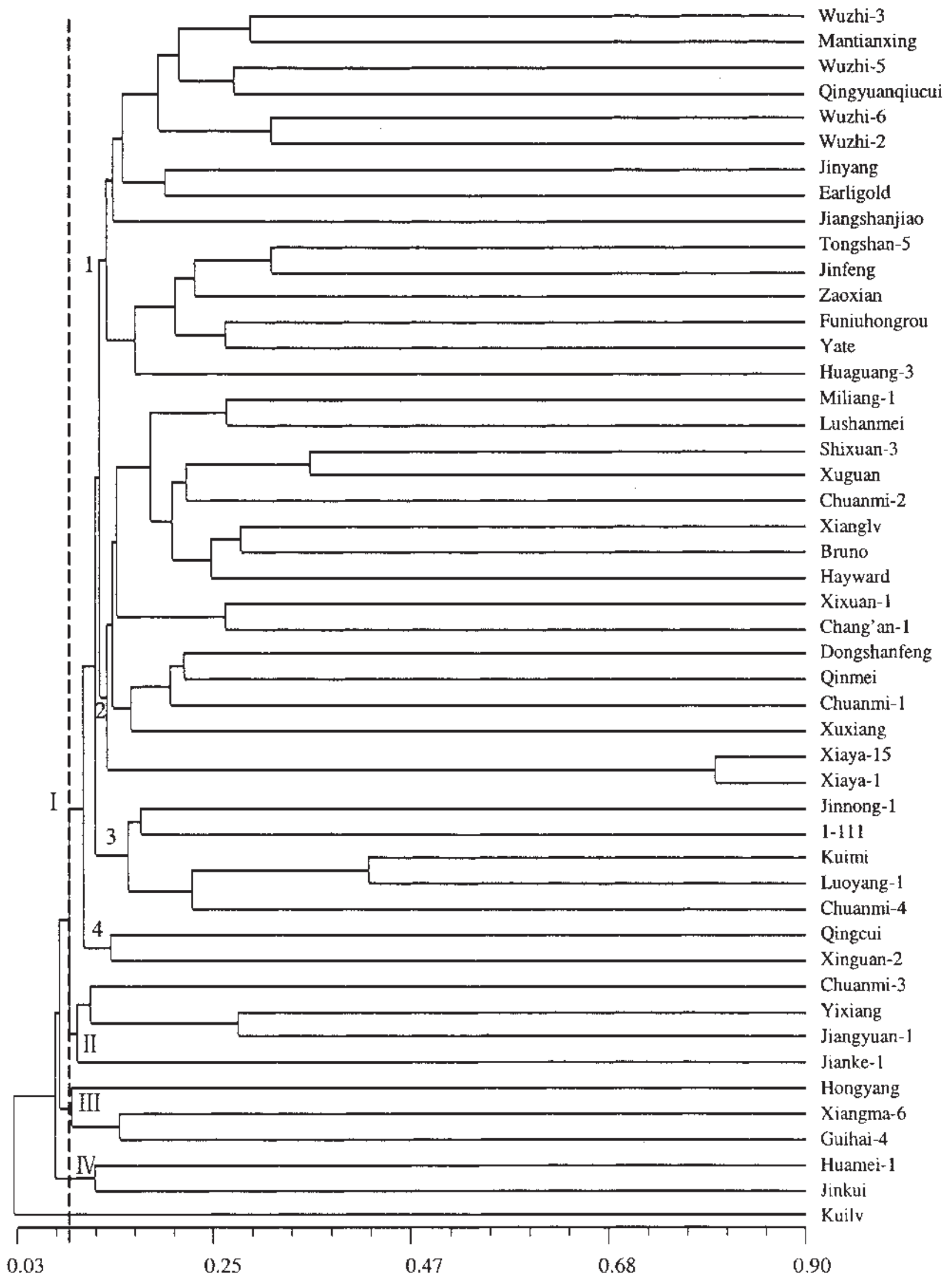

Fig. 1 SSR-based UPGMA dendrogram of Dice coefficients of genetic similarity among 48 kiwifruit cultivars or selections. All genotypes were separated into four major taxa groups labeled as I, II, III, and IV at the cut-off point $\left(\mathrm{D}_{1}=0.09\right)$, which was depicted as a vertical dashed line. Cluster I was further divided into four subclusters reflecting pedigree relationships and/or geographic origins of genotypes. 
cultivars and selections from both A. chinensis and A. deliciosa, suggesting that natural hybridization occurs frequently between these two closely related species within sympatric distributed areas. Almost all the cultivars and selections in this cluster were selected from the wild, and in fact, A. chinensis and A. deliciosa were treated as two taxonomic varieties (var. chinensis and var. hospita) within single species A. chinensis until the late 1980 s (Liang and Ferguson, 1986). Cluster II and cluster III included four and three $A$. chinensis cultivars, respectively, while cluster IV was comprised of two A. deliciosa cultivars. The cultivar, Kuilv, of $A$. arguta was separated from these clusters.

Cluster I could be further divided into four subclusters that appeared to reflect either known pedigree relationships or geographic origins of cultivars (Fig.1). The first subcluster contained all $A$. chinensis cultivars except two interspecific hybrids and one $A$. deliciosa cultivar. The two interspecific hybrid cultivars, Mantianxing and Jiangshanjiao, were derived from an interspecific cross of the female A. chinensis parent 'Wuzhi-3' with a male parent of $A$. eriantha selection (EA1998YN). Most cultivars in this subcluster were selected from Hubei and the bordering areas between Hubei and Jiangxi provinces (Huang et al., 2001). The second subcluster was comprised mostly of $A$. deliciosa cultivars except two closely related $A$. chinensis selections ('Xiaya-1' and 'Xiaya-15'). This group appeared to be a representation of original gene pool of 'Hayward' and its derivatives because cultivars 'Shixuan-3', 'Xuguan' and 'Xianglv' were seedling selections from 'Hayward' and the old New Zealand cultivar, Bruno that was also derived from the original seeds introduced into New Zealand in 1904 (Ferguson and Bollard, 1990; Huang et al., 2001). The third subcluster included all $A$. chinensis cultivars selected from Hubei and Henan provinces, while the fourth subcluster had two cultivars of A. deliciosa selected from Sichuan province.

\section{Discussion}

SSR markers are hypervariable and can be used efficiently for identification of kiwifruit cultivars. The range of nine to 38 alleles per locus observed in this study is much higher than that of seven to 17 alleles per locus reported previously (Huang et al., 1998). The difference was simply due to a wider array of cultivars and selections, which had diverse genetic backgrounds and geographic origins, as well as different ploidy levels (Table 1). This result is also well reflected by low individual allelic frequencies, because $71.8 \%$ of the alleles had allelic frequency $<0.05$ (Table 2). The value of mean number of 23.7 alleles per locus observed in this study is high in comparison to the reported values of SSR studies conducted in other plant species with similar ecological and life-history characteristics of wide geographic range, outcrossing and long-lived woody perennials, such as olive (Olea europaea L.), 3.0 alleles per locus (Cipriani et al., 2002); Citrus, 5.5 (Kijas et al., 1995); tea crabapple, 9.4 (Benson et al., 2001); blueberry (Vaccinium corymbosum L.), 7.9 (Levi and Rowland, 1997); avocado (Persea americana M.), 9.5 (Lavi et al., 1994); Pyrus, 11.0 (Yamamoto et al., 2001); apple (Malus domestica Borkh), 12.1 (Hokanson et al., 1998); cherry (Prunus L. sp.), 10.7 (Cantini et al., 2001); black cherry (Prunus serotina L.), 13.5 (Downey and Iezzoni, 2000); and bur oak (Quercus macrocarpa M.), 14.3 (Dow et al., 1995). But it is similar to the value reported for grape cultivars, 27.6 alleles per locus (Lamboy and Alpha, 1998). The mean gene diversity of 0.92 across all loci in kiwifruit was also found to be higher than that in other plants such as olive, 0.55 (Cipriani et al., 2002); apple, 0.71 (Hokanson et al., 1998); tea crabapple, 0.76 (Benson et al., 2001); and cherry, 0.81(Cantini et al., 2001). The high ploidy level of A. deliciosa (hexaploid), different ploidy races (diploid and tetraploid) of $A$. chinensis, and ploidy origins (allohexaploid in A. deliciosa and autotetraploid in A. chinensis) (Huang et al., 1997; Testolin and Ferguson, 1997) might explain the high genetic variation of SSRs in kiwifruit. In addition, 19 null alleles provided supplemental genetic information to enhance the identification of kiwifruit cultivars. The inheritance of null alleles in Actinidia species has not yet been subjected to investigation and we believe this is the first case ever reported for SSR null alleles in Actinidia species. Genetic significance of SSR null allele segregation has proven to be of importance to human genetics (Callen et al., 1993) and should be worthy of further investigation in plant genetics.

Of 211 alleles detected in A. chinensis and A. deliciosa, 133 alleles were common to both $A$. chinensis and A. deliciosa $(63.0 \%)$, with 33 and 36 alleles specific to $A$. chinensis (15.6\%) and $A$. deliciosa $(17.1 \%)$, respectively. This suggests that $75.6 \%$ of the alleles detected in A. deliciosa were from a shared gene pool of A. chinensis. Morphologically, the two species are very similar and a close phylogenetic relationship between $A$. chinensis and $A$. deliciosa has been demonstrated in previous investigations (Cipriani et al., 1996; Huang et al., 1997; Huang et al., 2002; Testolin and Ferguson, 1997). Our results agree with the hypothesis that $A$. chinensis is the sole progenitor of hexaploid $A$. deliciosa based on the observation of two species sharing $85 \%$ of allozymes (Testolin and Ferguson, 1997). Further partitioning the genetic variation of $A$. chinensis and A. deliciosa as a species complex revealed only $1.3 \%$ genetic variation between the species $(G s t=0.013)$ and provided additional evidence to support the hypothesis (data not shown).

One major application of molecular markers in germplasm repository management is marker aided conservation (MAC) for formulating appropriate collection policies. Therefore, information on genetic variability contained in individual cultivar is of great value to kiwifruit repository curators. Considerable differences of genetic variability among these 48 cultivars and selections were revealed by measuring mean number of alleles per locus (A), percentage of polymorphic loci (P) and direct count heterozygosity $\left(\mathrm{H}_{\mathrm{o}}\right)$ for each cultivar and selections (Table 1$)$. Within the $A$. chinensis cultivar group, tetraploids had higher values of $\mathrm{A}, \mathrm{P}$, and $\mathrm{H}_{\mathrm{o}}$ than diploids $(\mathrm{A} \geq 2.3$ in tetraploids vs. $\mathrm{A} \leq 1.9$ in diploids; $\mathrm{P} \geq 77.8 \%$ vs. $\mathrm{P} \leq 66.7 \% ; \mathrm{H}_{\mathrm{o}} \geq 0.50$ vs. $\mathrm{H}_{\mathrm{o}} \leq 0.33$ ), except for 'Earligold' with a high $\mathrm{P}(89.4 \%)$ and $\mathrm{H}_{\mathrm{o}}(0.44)$. Similarly, all A. deliciosa genotypes were hexaploids and, in general, had even higher genetic variability than tetraploid $A$. chinensis. Thus, the A. deliciosa cultivar group showed higher $\mathrm{A}, \mathrm{P}$ and $\mathrm{H}_{\mathrm{o}}$ than the A. chinensis cultivar group (Table 1). In contrast with no relationship observed between ploidy and number of alleles of isozymes (Testolin and Ferguson, 1997), the positive correlation between genetic variability and ploidy levels found here suggests that polyploidy plays an important role in maintaining genetic diversity. This should supplement valuable information for the selection potential in kiwifruit breeding programs (Huang et al., 2000). SSRs provided unique identification for 48 kiwifruit cultivars and selections, which was a substantial improvement in discrimination effectiveness compared with a $77 \%$ partial discrimination of 13 kiwifruit cultivars using RAPD markers (Cipriani et al., 1996). In fact, a single SSR locus UDK 96-414 can generate sufficient numbers of 'allelic phenotypes' for as many as 47 kiwifruit genotypes. This result underlines the potential that informative markers can efficiently reduce the number of 
SSR loci required for reliable identification of kiwifruit cultivars. Nevertheless, the SSR profile for each cultivar and selection in Table 3 furnishes the first benchmark of kiwifruit fingerprints informative to germplasm repository management and nurseries engaged in commercial kiwifruit propagation.

In conclusion, fingerprint profiling using SSR markers is a useful and reliable method for establishing genetic identities of kiwifruit cultivars and selections. SSRs also provide an improved discrimination tool for evaluating genetic diversity and relatedness compared to RAPD markers. SSRs, when genetically defined and properly used, should provide a useful reference for germplasm curators for developing sampling strategies and managing germplasm repositories and for breeders for parental selection.

\section{Literature Cited}

Ausubel, F.M., R. Brent, R.E. Kingston, D.D. Moore, J.G. Seidman, J.A. Smith, and K. Stuhl. 1987. Current protocols in molecular biology. Wiley, New York.

Benson, L.L., W.F. Lamboy, and R.H. Zimmerman. 2001. Molecular identification of Malus hupehensis (tea crabapple) accessions using simple sequence repeats. HortScience 36: 961-966.

Botta, L., N.S. Scott, I. Eynard, and M.R. Thomas. 1995. Evaluation of microsatellite sequence tagged site markers for characterizing Vitis vinifera cultivars. Vitis 34:99-102.

Callen, D.F., A.D. Thompson, Y. Shen, H.A. Phillips, R.I. Richards, J.C. Mulley, and G.R. Sutherland. 1993. Incidence and origin of "null" alleles in the $(\mathrm{AC})_{\mathrm{n}}$ microsatellite markers. Amer. J. Human. Genet. 52:922-927.

Cantini, C., A.F. Iezzoni, W.F. Lamboy, M. Boritzki, and D. Struss. 2001. DNA fingerprinting of tetraploid cherry germplasm using simple sequence repeats. J. Amer. Soc. Hort. Sci. 126:205-209.

Chat, J., L. Chalak, and R.J. Petit. 1999. Strict paternal inheritance of chloroplast DNA and maternal inheritance of mitochondrial DNA in intraspecific crosses of kiwifruit. Theor. Appl. Genet. 99:314-322.

Cipriani, G., R. Testolin, and M. Morgante. 1995. Paternal inheritance of plastids in interspecific hybrids of the genus Actinidia revealed by PCR amplification of chloroplast DNA fragments. Mol. Gen. Genet. 247:693-697.

Cipriani, G., R. Di-Bella, and R.Testolin. 1996. Screening RAPD primers for molecular taxonomy and cultivar fingerprinting in the genus Actinidia. Euphytica 90:169-174.

Cipriani, G., M.T. Marrazzo, R. Marconi, and A. Cimato. 2002. Microsatellite markers isolated in olive (Olea europaea L.) are suitable for individual fingerprinting and reveal polymorphism within ancient cultivars. Theor. Appl. Genet. 104:223-228.

Cui, Z.-X. 1993. Actinidia in China. Shandong Scientific Press, Jinan, Shandong.

Dice, L.R. 1945. Measures of the amount of ecological association between species. Ecology 26:297-302.

Dow, B.D., M.V. Ashley, and H.F. Howe. 1995. Characterization of highly variable $(\mathrm{GA} / \mathrm{CT})_{\mathrm{n}}$ microsatellites in the bur oak (Quercus macrocarpa). Theor. Appl. Genet. 91:137-141.

Downey, S.D. and A.F. Iezzoni. 2000. Polymorphic DNAmarkers in black cherry (Prunus serotina) are identified using sequences from sweet cherry, peach, and sour cherry. J. Amer. Soc. Hort. Sci. 125:76-80.

Ferguson, A.R. and E.G. Bollard. 1990. Domestication of the kiwifruit, p. 165-246. In: I.J. Warrington and G.C. Weston (eds.). Kiwifruit: Science and management. Ray Richard Publ, Auckland, N.Z.

Gulsen, O. and M.L. Roose. 2001. Lemon: Diversity and relationships with selected Citrus genotypes as measured with nuclear genome markers. J. Amer. Soc. Hort. Sci. 126:309-317.

Hokanson, S.C., A.K. Szewc-McFadden, W.F. Lamboy, and J.R. McFerson. 1998. Microsatellite (SSR) markers reveal genetic identities, genetic diversity and relationships in Malus domestica Borkh. core subset collection. Theor. Appl. Genet. 97:671-683.

Huang, H. 1999. Nuove varieta di Actinidia deliciosae A. chinensis ottenute in China. Frutticoltura 61:18-22.

Huang, H., and A.R. Ferguson. 2001. Kiwifruit in China. N.Z. J. Crop Hort. 29:1-14.

Huang, H., F. Dane, Z.-R. Wang, Z.-W. Jiang, R.-H. Huang, and S.-M. Wang. 1997. Isozyme inheritance and variation in Actinidia. Heredity 78:328-336.

Huang, H., J. Gong, S. Wang, Z. He, Z. Zhang, and J. Li. 2000. Genetic diversity in the genus Actinidia (in Chinese). Chinese Biodiversity 8: $1-12$.

Huang, H., S. Wang, Z. Zhang, Z. Jiang, and J. Gong. 2001. Efficiently growing kiwifruit (in Chinese). Jindun Press, Beijing.

Huang, H., Z. Li, J. Li, T.L. Kubisiak, and D.R. Layne. 2002. Phylogenetic relationships in Actinidia as revealed by RAPD analysis. J. Amer. Soc. Hort. Sci. 127:759-766.

Huang, W.G., G. Cipriani, M. Morgante, and R. Testolin. 1998. Microsatellite DNA in Actinidia chinensis: Isolation, characterization, and homology in related species. Theor. Appl. Genet. 97:1269-1278.

Kijas, J.M.H., J.C.S. Fowler, and M.R. Thomas. 1995. An evaluation of sequence-tagged microsatellite site markers for genetic analysis within Citrus and related species. Genome 38:349-355.

Lamboy, W.F. and C.G. Alpha. 1998. Using simple sequence repeats (SSRs) for fingerprinting germplasm accessions of grape (Vitis L.) species. J. Amer. Soc. Hort. Sci. 123:182-188.

Lavi, U., M. Akkaya, A. Bhagwat, E. Lahav, and P.B. Cregan. 1994. Methodology of generation and characteristics of simple sequence repeat DNA markers in avocado (Persea americana M.). Euphytica 80:171-177.

Levi, A. and L.J. Rowland. 1997. Identifying blueberry cultivars and evaluating their genetic relationships using randomly amplified polymorphic DNA (RAPD) and simple sequence repeat-(SSR-) anchored primers. J. Amer. Soc. Hort. Sci. 122:74-78.

Liang, C.F. and A.R. Ferguson. 1986. The botanical nomenclature of the kiwifruit and related taxa. N.Z. J. Bot. 24:183-184.

Nei, M. 1978. Estimation of average heterozygosity and genetic distance from a small number of individuals. Genetics 89:583-590.

Nei, M. and W.H. Li. 1979. Mathematical model for studying genetic variation in term of restriction endonucleases. Proc. Natl. Acad. Sci. USA. 76:5269-5273.

Palombi, M.A. and C. Damiano. 2002. Comparison between RAPD and SSR molecular markers in detecting genetic variation in kiwifruit (Actinidia deliciosa A. Chev). Plant Cell Rpts. 20:1061-1066.

Testolin, R. and G. Cipriani. 1997. Paternal inheritance of chloroplast DNA and maternal inheritance of mitochondrial DNA in the genus Actinidia. Theor. Appl. Genet. 94:897-903.

Testolin, R. and A.R. Ferguson. 1997. Isozyme polymorphism in the genus Actinidia and the origin of the kiwifruit genome. Syst. Bot. 22: 685-700.

Wagner, D.B., G.R. Furnier, M.A. Saghai-Maroof, S.M. Williams, B.P. Dancik, and R.W. Allard. 1987. Chloroplast DNA polymorphisms in lodgepole and jack pines and their hybrids. Proc. Natl. Acad. Sci. USA 84:2097-2100.

Weising, K., R.W.M. Fung, D.J. Keeling, R.G. Atkinson, and R.C. Gardner. 1996. Characterization of microsatellites from Actinidia chinensis. Mol. Breed. 2:117-131.

Weir, B.S. 1996. Genetic data analysis II. Sinauer Assoc., Sunlander, Mass.

Xu, K.-R. and D.-Z. Li. 1983. A preliminary research on the numerical classification of the genus Panax from China. Acta Phytotaxonomica Sinica 21:34-43.

Yamamoto, T., T. Kimura, Y. Sawamura, K. Kotobuki, Y. Ban, T. Hayashi, and N. Matsuta. 2001. SSRs isolated from apple can identify polymorphism and genetic diversity in pear. Theor. Appl. Genet. 102:865-870. 